Revision 2. 4-9-15

\title{
Iridium Catalyzed Reversible Dehydrogenation - Hydrogenation of Quinoline Derivatives Under Mild Conditions
}

Michael G. Manas ${ }^{+}$, Liam S. Sharninghausen ${ }^{+}$, Elisa Lin, Robert H. Crabtree*

Department of Chemistry, Yale University, 225 Prospect Street, New Haven, Connecticut 06520, United States

*robert.crabtree@yale.edu

${ }^{+}$These authors contributed equally

Keywords: Acceptorless Dehydrogenation; Hydrogen Storage; LOHCs; Heterocycles

\begin{abstract}
The potential of a hydrogen-based energy economy is limited by the fact that hydrogen gas is difficult to store and transport. Storing hydrogen in the form of liquid organic hydrogen-carriers (LOHCs) is a highly attractive alternative to current options but it requires the development of catalytic means of reversibly hydrogenating and dehydrogenating these carriers under mild conditions and ideally using a single catalyst for both processes. We report the optimization of two families of previously reported hydrogenation catalysts for the reverse reaction, dehydrogenation of N-heterocyclic substrates. These complexes are capable of catalyzing both dehydrogenation and hydrogenation reactions in alternation, giving high yields in both directions. Importantly,
\end{abstract}


our complexes do not require high temperatures, high pressures of $\mathrm{H}_{2}$ or strong base for the hydrogenation step.

\section{Introduction}

The development of highly efficient catalysts for the reversible hydrogenation and dehydrogenation of suitable organic molecules is of great interest to the field of alternative energy research. ${ }^{1}$ Hydrogenated organic liquids can in principle be used to transport hydrogen in the covalently bound form, with subsequent catalyzed release of free $\mathrm{H}_{2}{ }^{2,3}$ Ongoing research at GE Global Research and elsewhere is directed toward using such compounds in fuel cells or flow batteries. ${ }^{4}$ The use of such liquid organic hydrogen carrier molecules (LOHCs) holds promise as an attractive alternative to the transportation and storage of gaseous hydrogen, which may otherwise require high pressure cylinders that give rise to a large weight penalty. ${ }^{2,5}$ The dehydrogenated carrier molecule can then be recycled and regenerated by catalytic hydrogenation. The current global energy transport and storage infrastructure utilizes liquid hydrocarbon fossil fuels and could arguably be adapted for LOHCs with less disruption than for some other strategies. $^{2-6}$ Prior work indicates that the presence of a heteroatom in the LOHC minimizes the unfavorable thermodynamics of the dehydrogenation reaction, allowing for both hydrogenation and dehydrogenation to occur under mild conditions. ${ }^{6}$ In order to make use of heterocycles as hydrogen storage molecules, both the catalytic hydrogenation and dehydrogenation processes must be feasible under mild conditions. ${ }^{6}$ A number of catalysts, both heterogeneous ${ }^{7,8,9,10}$ and homogeneous, ${ }^{11,12,13,14}$ can bring about either hydrogenation or dehydrogenation of $\mathrm{N}$-heterocyclic substrates, but there are 
very few homogeneous catalysts capable of carrying out both reactions on model quinoline derivatives under mild conditions. ${ }^{12-14}$ Such a catalyst would be potentially applicable to reversible hydrogen storage, by allowing for easy hydrogenation and later dehydrogenation of an LOHC all in one reactor and without the need to add or remove any additional compounds aside from $\mathrm{H}_{2}$ gas.

The iridium complexes reported by Fujita et al. are unusual in being very efficient catalysts for both the hydrogenation and dehydrogenation of quinolines. ${ }^{12,14}$ Although the conditions reported for the hydrogenation of quinaldine were not ideal, requiring either elevated temperature or $\mathrm{H}_{2}$ pressures of 3-10 atm, they were able to dehydrogenate tetrahydroquinaldine in $p$-xylene at reflux $\left(145^{\circ} \mathrm{C}\right)$ in less than 24 hours. Xiao and coworkers recently found an iridium pincer complex to be highly active for dehydrogenation of a range of tetrahydroquinolines under even milder conditions $\left(74{ }^{\circ} \mathrm{C}\right)$ in 2,2,2-trifluoroethanol; ${ }^{11 \mathrm{~d}}$ however, the corresponding hydrogenation was achieved only after modification of the pincer ligand. ${ }^{11 \mathrm{e}}$ Recently, the Jones group discovered a "twoway" system for the sequential hydrogenation-dehydrogenation of quinoline derivatives with an iron(II)-(PNP) pincer complex. ${ }^{12}$ While this system is not as active as the Fujita system, it utilizes a much cheaper catalyst which makes it very attractive. Unfortunately, this system also requires $10 \mathrm{~mol} \%$ of strong base, in addition to 5-10 atm $\mathrm{H}_{2}$, in order to carry out the hydrogenation reaction. Interestingly, in contrast to the Fujita system, these iron(II) complexes are not hindered by sterically unencumbered substrates which might have been thought likely to bind to the active site via the $\mathrm{N}$ lone pair and inhibit the reaction. 
Prior work in our lab has focused on two families of iridium catalysts capable of efficiently catalyzing the conversion of quinaldine to 1,2,3,4-tetrahydroquinaldine under $1 \mathrm{~atm}$ of $\mathrm{H}_{2}$ at room temperature (Figure 1). ${ }^{15,16}$ To our knowledge, these catalysts still rank amongst the most efficient homogeneous hydrogenation catalysts for such reactions, only being surpassed recently by a family of $\mathrm{Cp} * \operatorname{Ir}(\mathrm{III})(\mathrm{N}-\mathrm{C}) \mathrm{Cl}$ complexes, ${ }^{10 \mathrm{e}}$ and are superior to the Fujita catalysts discussed above with regards to hydrogenation activity under mild conditions. The first generation precatalyst, $\mathbf{1}$, and its activated form, $\mathbf{2}$ (Figure 2), were found to be the more active of our two classes of complexes. Compounds $\mathbf{1}$ and $\mathbf{2}$ are capable of catalyzing the reduction of a wider range of $\mathrm{N}$ heterocyclic substrates than complex, $\mathbf{3}$, but at the cost of solvent scope. Both classes of catalysts are believed to operate via an outer-sphere mechanism entailing the sequential delivery of a proton followed by a hydride to the unbound substrate from a coordinated $\mathrm{H}_{2}$ molecule. As a natural extension of this work, we sought to explore the potential for dehydrogenation of saturated $\mathrm{N}$-heterocyclic substrates under mild conditions using these same families of complexes. Based on the principles of microscopic reversibility, it is plausible to think that these catalysts would be competent for the reverse reaction and that the process could be optimized by variation of the conditions. 


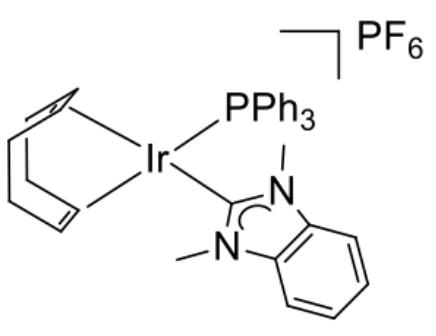

1

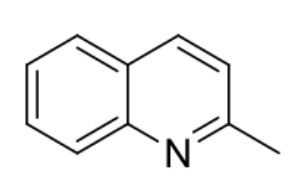

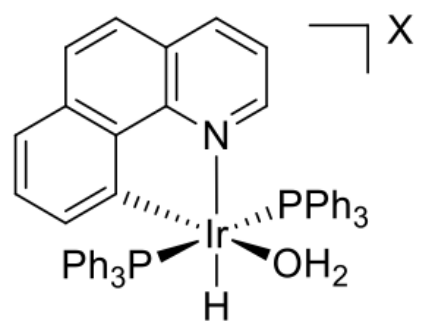

3a: $X=\mathrm{BAr}_{4}$

3b: $\mathrm{X}=\mathrm{PF}_{6}$

3

[lr] (1-5 mol\%)

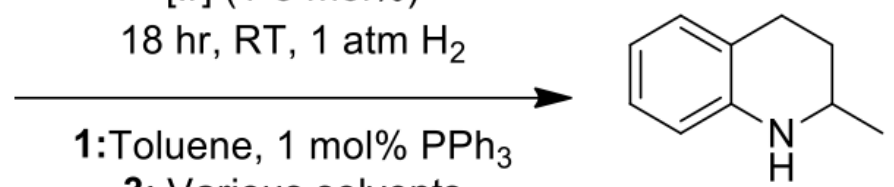

3: Various solvents

Figure 1. Compounds $\mathbf{1}$ and $\mathbf{3}$ are highly active precatalysts for quinaldine hydrogenation under mild conditions.

\section{Results and Discussion}

Precatalyst $\mathbf{1}-\mathbf{P F}_{\mathbf{6}}$ was first screened for the dehydrogenation of $1,2,3,4$ tetrahydroquinaldine in toluene in the presence of 1 equivalent of triphenylphosphine. It was found that in reactions run below reflux temperature, no appreciable reactivity was observed; however, small quantities of dehydrogenated product were observed when the reaction was refluxed (Table 1, Entries 1-2). This is believed to arise in large part from the reflux action itself sweeping the product $\mathrm{H}_{2}$ out of the solution, driving the equilibrium in the dehydrogenative direction by mass action, as previously seen in catalytic alkane dehydrogenation. ${ }^{17}$ In order to increase the catalytic activity, $\mathbf{2}$, the proposed active catalyst, was preformed according to a previously published procedure by stirring $1-\mathbf{P F}_{6}$ under 1 atm of $\mathrm{H}_{2}$ and in the presence of 1 equivalent of triphenylphosphine (Figure 2). Indeed, $\mathbf{2}$ gave a marked increase in yield under identical 
conditions (Table 1, Entries 3-4). By changing the solvent to chlorobenzene (Table 1, Entry 5) or $p$-xylene and thus increasing the reflux temperature, activity increased further, with complete conversion observed after 72 hours (Table 1, Entry 7). In contrast, under these optimized conditions, less conversion was observed for 1,2,3,4-tetrahydroquinoline (Table 1, Entry 8) than for the more sterically hindered 1,2,3,4-tetrahydroquinaldine, having an additional methyl group at the 2-position. This result follows the trend observed in our hydrogenation work where substrates lacking a bulky substituent at the 2position give lower yields, presumably due to coordination of the nitrogen lone-pair to the metal, leading to catalyst deactivation.

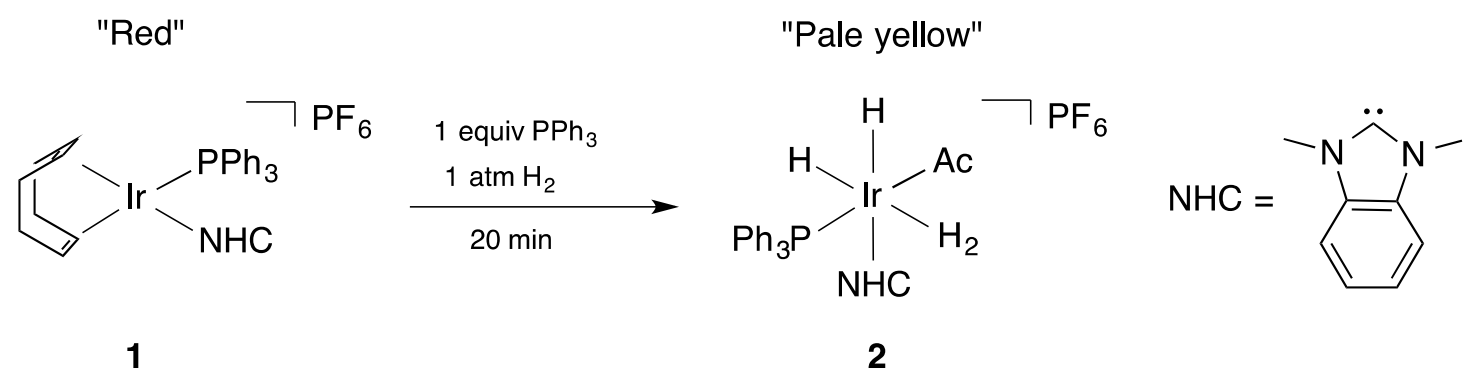

Figure 2. Formation of active species 2 by hydrogenation in the presence of $\mathrm{PPh}_{3}$. The conversion from can be tracked visually by a distinct color change. 


\section{Table 1. Dehydrogenation of Tetrahydroquinoline Derivatives by 1}

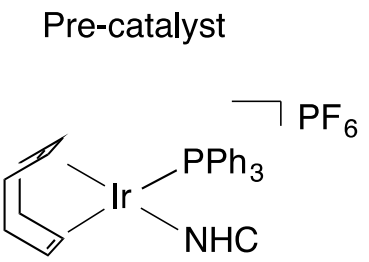

1

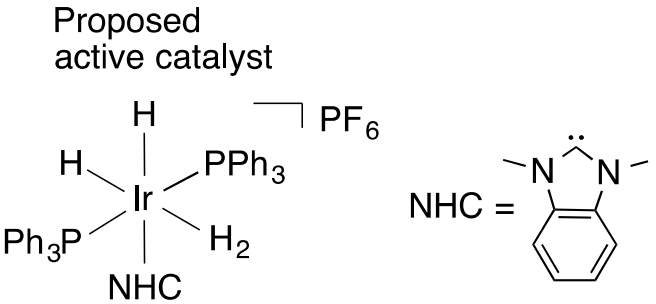<smiles>[R]C1CCc2ccccc2N1</smiles>

[Ir] $(5 \mathrm{~mol} \%)$

$24 / 72 \mathrm{~h}$

2<smiles>[R]c1ccc2ccccc2n1</smiles>

\begin{tabular}{llllll}
\hline Entry & Solvent & R & Temp. $\left({ }^{\circ} \mathbf{C}\right)$ & Time (h) & Yield \\
\hline 1 & Toluene & Me & 80 & 24 & $<2 \%$ \\
2 & Toluene & Me & 115 & 24 & $7 \%$ \\
3 & Toluene $^{\mathrm{a}}$ & $\mathrm{Me}$ & 80 & 24 & $<2 \%$ \\
4 & Toluene $^{\mathrm{a}}$ & $\mathrm{Me}$ & 115 & $24 / 72$ & $10 / 20 \%$ \\
5 & Chlorobenzene $^{\mathrm{a}}$ & $\mathrm{Me}$ & 135 & $24 / 72$ & $45 / 85 \%$ \\
6 & $p$-Xylene & $\mathrm{Me}$ & 145 & 24 & $12 \%$ \\
7 & $p$-Xylene $^{\mathrm{a}}$ & $\mathrm{Me}$ & 145 & $24 / 72$ & $48 / \sim 95 \%$ \\
8 & $p$-Xylene $^{\mathrm{a}}$ & $\mathrm{H}$ & 145 & $24 / 72$ & $19 / 61 \%$ \\
\hline
\end{tabular}

Experiments run under 1 atm $\mathrm{N}_{2}, 1,2,3,4$-tetrahydroquinaldine or 1,2,3,4-tetrahydroquinoline (0.112 mmol), 1 and $\mathrm{PPh}_{3}$ (both $5 \mathrm{~mol} \%$ with respect to substrate), solvent $(3 \mathrm{ml}) .{ }^{\mathrm{a}}$ Experiments run with pre-activation of catalyst by heating to $100{ }^{\circ} \mathrm{C}$ and bubbling $\mathrm{H}_{2}$ gas for 20 minutes prior to catalysis. Yields determined by ${ }^{1} \mathrm{H}$ NMR spectroscopy using 1,3,5-trimethoxybenzene as an internal standard. Control experiments for these reactions can be found in Table S1. 
Following our prior work, ${ }^{16}$ derivatives of $\mathbf{3}$ were also screened for the dehydrogenation of tetrahydroquinoline compounds (Table 2). Variants of complex $\mathbf{3}$ are generally less active as hydrogenation catalysts than $\mathbf{1}$ but do not require the addition of phosphine additives or pre-activation with $\mathrm{H}_{2}$. In analogy to our prior hydrogenation studies, $\mathbf{1}$ was more active than $\mathbf{3 b}$ (Table 2); over 24 hours in $p$-xylene at $145^{\circ} \mathrm{C}, \mathbf{1}$ gave almost twice the yield that $\mathbf{3 b}$ did. Change of the counterion from $\mathrm{PF}_{6}$ to tetrakis[3,5bis(trifluoromethyl)phenyl]borate $\left(\mathrm{B}\left(\mathrm{Ar}^{\mathrm{F}}\right)_{4}\right)$ had little effect (Table 2, Entries 1-2, 6-7). Significantly, changing the solvent to chlorobenzene gives a marked increase in yield (Table 2, Entry 5), likely due to the increased solubility of the complex or possibly also to its mild coordinating power. As was observed with $\mathbf{1}$, increasing the temperature and reaction time increased the overall yield and reactivity proved to be greater with $1,2,3,4-$ tetrahydroquinaldine than with 1,2,3,4-tetrahydroquinoline (Table 2, Entries 2-5). Additionally, both variants of $\mathbf{3}$ were tested for dehydrogenation in the presence of a $\mathrm{H}_{2}$ accepting substrate (N-benzylideneaniline) in an attempt to further drive the dehydrogenation (Table 2, Entries 6-8). A slight increase in activity was observed but yields remained relatively low. 
Table 2. Dehydrogenation of Tetrahydroquinoline Derivatives by 3a and 3b

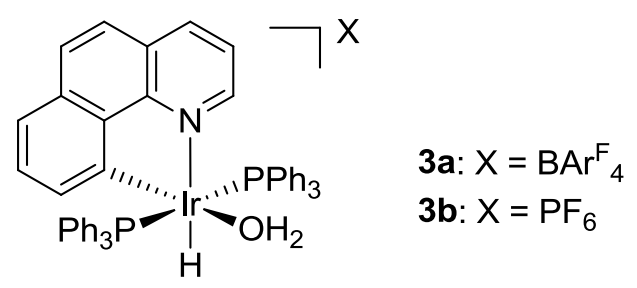

3<smiles>CC1CCc2ccccc2N1</smiles>

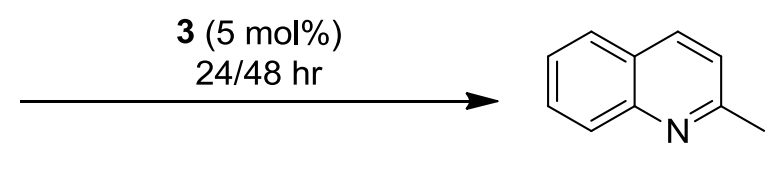

\begin{tabular}{|c|c|c|c|c|c|c|}
\hline Entry & Complex & Solvent & $\mathbf{R}$ & Temp. $\left({ }^{\circ} \mathrm{C}\right)$ & $\begin{array}{l}\text { Time } \\
\text { (hour) }\end{array}$ & Yield \\
\hline 1 & $\mathbf{3 a}$ & Toluene & $\mathrm{H}$ & 115 & $24 / 48$ & $8 / 17 \%$ \\
\hline 2 & $3 \mathbf{b}$ & Toluene & $\mathrm{H}$ & 115 & $24 / 48$ & $9 / 18 \%$ \\
\hline 3 & $3 \mathbf{b}$ & Toluene & $\mathrm{Me}$ & 115 & 24 & $16 \%$ \\
\hline 4 & $3 \mathbf{b}$ & $p$-Xylene & $\mathrm{Me}$ & 145 & 24 & $21 \%$ \\
\hline 5 & $3 \mathbf{b}$ & Chlorobenzene & $\mathrm{Me}$ & 135 & $24 / 72$ & 46 / 66\% \\
\hline 6 & $3 \mathbf{b}$ & $p$-Xylene ${ }^{\mathrm{a}}$ & $\mathrm{Me}$ & 145 & 24 & $25 \%$ \\
\hline 7 & $\mathbf{3 a}$ & Toluene $^{\mathrm{a}}$ & $\mathrm{H}$ & 115 & 24 & $13 \%$ \\
\hline 8 & $\mathbf{3 b}$ & Toluene $^{a}$ & $\mathrm{H}$ & 115 & $24 / 48$ & $18 / 29 \%$ \\
\hline \multicolumn{7}{|c|}{ 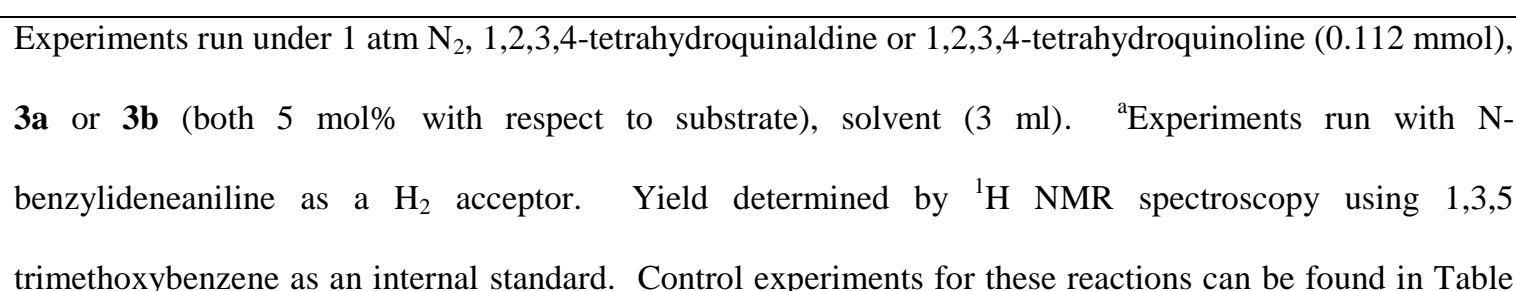 } \\
\hline trii & en & rnal standard. & & nts for the & & \\
\hline
\end{tabular}


In order to investigate the robustness of complexes $\mathbf{1}$ (preactivated to form $\mathbf{2}$ ) and $\mathbf{3 b}$ under the reaction conditions, which relates to their potential to perform 2-way dehydrogenation-hydrogenation reactions, we monitored their activity over time using a gas-burette at low catalyst loading (0.5 mol \%) (Figure 3 and SI, page S2). Over 72 hours, $\mathbf{1}$ and $\mathbf{3 b}$ give TONs of 43 and 32, respectively, similar to TONs achieved by other heterocycle dehydrogenation systems. ${ }^{1 \mathrm{~d}, 12,13}$ The complexes show similar, approximately linear activity for the first $\sim 30 \mathrm{~h}$, with a TOF of approximately $0.8 \mathrm{~h}^{-1}$; however at longer times, complex $\mathbf{3 b}$ decreases in activity. This is in agreement with the 24 and 72 hour experiments in chlorobenzene (Table 1 entry 5; Table 2, Entry 5), where yield is similar for the two complexes after $24 \mathrm{~h}$, but is much higher for $\mathbf{1}$ after $72 \mathrm{~h}$. The latter complex may therefore better resist deactivation. Indeed, ${ }^{1} \mathrm{H}$ NMR spectra of a catalytic reaction mixture containing $\mathbf{3 b}$ show a hydride peak corresponding to $\mathbf{3 b}$ after $24 \mathrm{~h}(\sim 70 \%$ of added amount), while at $72 \mathrm{~h}$, this peak is no longer present, consistent with decomposition into inactive species. Because of the durability of $\mathbf{1}$, as well as its ability to perform the dehydrogenation reaction in high yield, we attempted dehydrogenation followed by hydrogenation using this complex. Notably, no activity for hydrogenation was observed after exposure to $\mathrm{H}_{2}$ at room temperature following a $72 \mathrm{~h}$ dehydrogenation reaction in p-xylene or chlorobenzene. 
Figure 3. Reaction Profiles for Dehydrogenation with Pre-catalysts 1 and 3b Generated by Gas-burette.

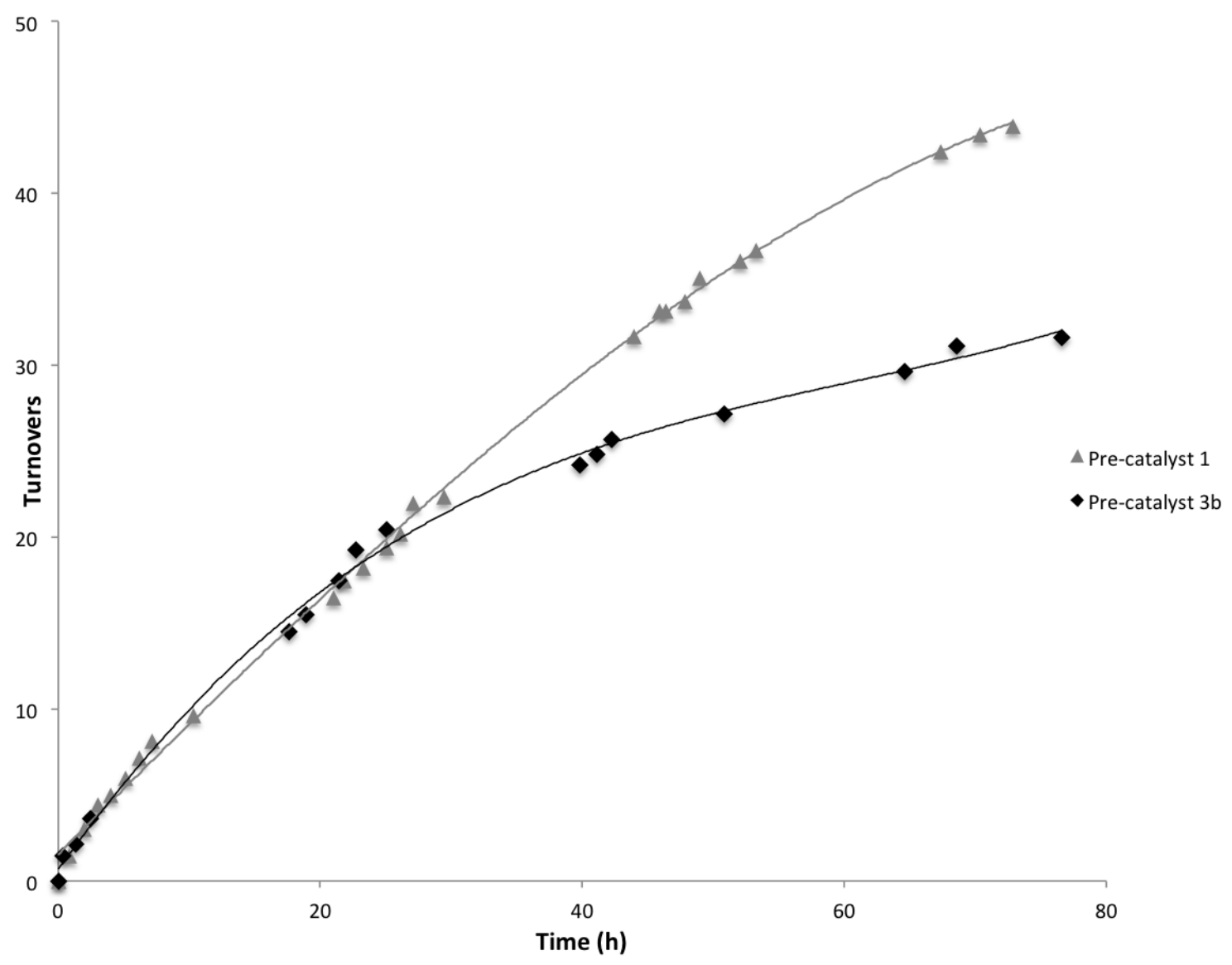

Experiments run with iridium complex $(0.02 \mathrm{mmol}, 0.5 \mathrm{~mol} \%)$, tetrahydroquinaldine $(4 \mathrm{mmol})$ and chlorobenzene $(10 \mathrm{~mL})$. Precatalyst 1 was pre-activated by adding 1 eq. $\mathrm{PPh}_{3}$, heating to $100{ }^{\circ} \mathrm{C}$ and bubbling $\mathrm{H}_{2}$ gas for 20 minutes prior to catalysis. Reaction progress was monitored by gas burette, with 1 TON defined as 2 molecules of $\mathrm{H}_{2}$ produced per molecule of catalyst (See SI for details).

In the hope of accomplishing dehydrogenation faster and potentially retaining enough active catalyst for the subsequent hydrogenation, we ran reactions at higher 
substrate and precatalyst concentrations (Table 3). Chlorobenzene was selected as solvent because it dissolves the iridium complexes at high concentration and has a relatively high boiling point. Indeed, for both $\mathbf{1}$ and $\mathbf{3 b}$, increasing the tetrahydroquinaldine concentration from 0.04 to $1.1 \mathrm{M}$ gives increased conversion for dehydrogenation over 24 $\mathrm{h}$ at $5 \%$ catalyst loading (Table 3, Entries 3 and 6). Following this improved dehydrogenation step, subsequent hydrogenation is possible under $1 \mathrm{~atm} \mathrm{H}_{2}$ at ambient temperature, giving $>95 \%$ yield for $\mathbf{1}$ and $75 \%$ yield for $\mathbf{3 b}$, thus demonstrating the ability of our catalysts to carry out both reactions in alternation as appropriate for a hydrogen storage application. Importantly, our complexes do not require high temperatures, high pressures of $\mathrm{H}_{2}$ or strong base for the hydrogenation step as in previous "2-way" systems, while giving slightly lower but comparable yields in both directions. ${ }^{12,13}$ Thus, we have developed a system for reversible quinaldine hydrogenation that functions under unprecedentedly mild conditions for the hydrogenation step. 
Table 3: Reversible dehydrogenation of tetrahydroquinaldine in chlorobenzene with 5 mol \% iridium complex under mild conditions

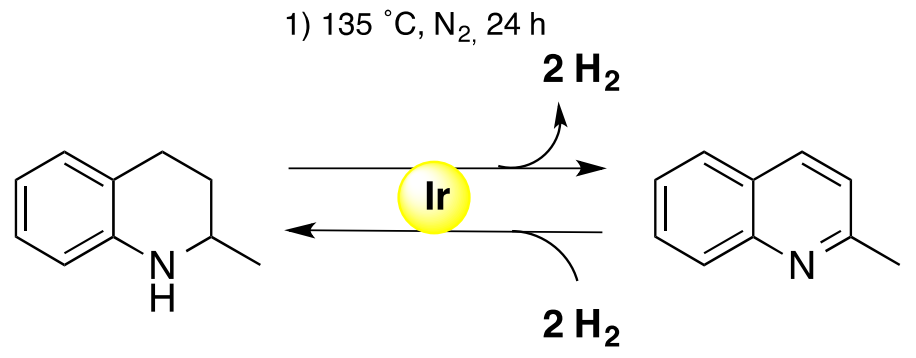

2) $25^{\circ} \mathrm{C}, 1 \mathrm{~atm} \mathrm{H}_{2}, 24 \mathrm{~h}$

\begin{tabular}{|c|c|c|c|c|}
\hline Entry & Complex & $\begin{array}{c}\text { Substrate } \\
\text { Concentration } \\
\text { (M) }\end{array}$ & $\begin{array}{c}\text { Dehydrogenation } \\
\text { yield }(\%)^{\mathbf{b}}\end{array}$ & $\begin{array}{l}\text { Hydrogenation } \\
\text { yield }(\%)^{b}\end{array}$ \\
\hline 1 & $1^{\mathrm{c}}$ & 0.04 & 45 & $-{ }^{\mathrm{a}}$ \\
\hline 2 & $1^{\mathrm{c}}$ & 0.24 & 63 & $-{ }^{\mathrm{a}}$ \\
\hline 3 & $1^{\mathrm{c}}$ & 1.1 & 73 & $>95$ \\
\hline 4 & $3 \mathbf{b}$ & 0.04 & 46 & $-^{\mathrm{a}}$ \\
\hline 5 & $3 \mathbf{b}$ & 0.24 & 60 & $-^{\mathrm{a}}$ \\
\hline 6 & $3 b$ & 1.1 & 85 & 76 \\
\hline
\end{tabular}

Experiments run with chlorobenzene, iridium complex (5 mol \%), tetrahydroquinaldine, and 1,3,5trimethoxybenzene as internal standard. Dehydrogenation reaction performed at reflux $\left(135{ }^{\circ} \mathrm{C}\right)$ for $24 \mathrm{~h}$. Subsequently, for entries 3 and 6 , reaction mixture cooled to room temperature and hydrogenation carried out by stirring for $24 \mathrm{~h}$ at ambient temperature under 1 atmosphere of $\mathrm{H}_{2} .{ }^{\mathrm{a}}$ Hydrogenation not attmepted for these entries. ${ }^{\mathrm{b}}$ Yields determined by ${ }^{1} \mathrm{H}$ NMR spectroscopy using 1,3,5-trimethoxybenzene as internal standard; Hydrogenation yield calculated as amount of quinaldine hydrogenated divided by initial amount of quinaldine after dehydrogenation step. ${ }^{\mathrm{c}} \mathrm{Complex}$ pre-activated by adding 1 eq. $\mathrm{PPh}_{3}$, heating to $100{ }^{\circ} \mathrm{C}$ and bubbling $\mathrm{H}_{2}$ gas for 20 minutes prior to catalysis. 


\section{Conclusion}

Two iridium catalysts previously developed by our group for the hydrogenation of Nheterocycles have been applied to the reverse reaction, dehydrogenation of the saturated N-heterocycles. In addition, these complexes are able to perform reversible dehydrogenation-hydrogenation reactions in sequence with high yields for both directions. Neither system surpassed the best prior "two-way" literature catalyst for the hydrogenation/dehydrogenation of quinaldine in terms of dehydrogenation efficiency ${ }^{12,14}$ but both $\mathbf{1}$ and $\mathbf{3}$ are much more efficient than the prior "two-way" systems for the hydrogenation of quinaldine.

\section{Experimental}

General Methods. The syntheses of the metal complexes were conducted under nitrogen using dry degassed solvents unless otherwise indicated. Solvents were dried and degassed prior to use. Iridium species used in these experiments were synthesized according to

literature procedures (see SI). ${ }^{14,15}$ All other reagents were commercially available from Airgas, Sigma-Aldrich, Alfa-Aesar and Strem Chemicals and used as received unless otherwise indicated. NMR spectra were recorded at room temperature on a 400 or 500 $\mathrm{MHz}$ Bruker or Varian spectrometer.

\section{Procedure for dehydrogenation of 1,2,3,4-tetrahydroquinaldine and 1,2,3,4-} tetrahydroquinoline using 1 . To a flame-dried $15 \mathrm{ml}$ Schlenk tube under nitrogen was added a stir bar, 1,2,3,4-tetrahydroquinaldine or 1,2,3,4-tetrahydroquinoline $(16.2 \mu \mathrm{l}$ and $14.1 \mu \mathrm{l}$ respectively, $0.112 \mathrm{mmol})$, trimethoxybenzene $\left(10.0 \mathrm{mg}\right.$, internal ${ }^{1} \mathrm{H}$ NMR 
standard), triphenylphosphine (5.5 mol\% with respect to 1,2,3,4-tetrahydroquinaldine, 1.6 $\mathrm{mg}$ ) and 1 (5 mol\% with respect to 1,2,3,4-tetrahydroquinaldine, $4.7 \mathrm{mg}$ ). Dry solvent (3 $\mathrm{ml}$ of toluene or $p$-xylene, sparged with $\mathrm{N}_{2}$ ) was then added to the flask. The flask was purged with $\mathrm{H}_{2}$ by bubbling through the solution for $~ 20$ minutes, activating the catalyst; a distinct color change from red-orange to yellow was observed. The $\mathrm{H}_{2}$ atmosphere was removed with three cycles of evacuation and $\mathrm{N}_{2}$ replacement, leaving the system under 1 atm of nitrogen with an oil bubbler outlet. The reaction mixture was then stirred and heated to just above the reflux temperature of the solution $\left(115^{\circ} \mathrm{C}\right.$ for toluene, $145^{\circ} \mathrm{C}$ for p-xylene) and aliquots were collected at 24, 48 and 72 hours. The solvent was removed in vacuo and the resulting mixture was redissolved in $\mathrm{CD}_{2} \mathrm{Cl}_{2}$. Conversion was assessed by comparative integration of the product and starting material peaks to the internal standard in the ${ }^{1} \mathrm{H}$ NMR spectrum. Spectra of pure quinaldine and 1,2,3,4-tetrahydroquinaldine from commercially obtained samples were used as peak references in identifying the products.

\section{Procedure for dehydrogenation of 1,2,3,4-tetrahydroquinaldine and 1,2,3,4-} tetrahydroquinoline using 3a and 3b. To a flame dried $15 \mathrm{ml}$ Schlenk tube under nitrogen was added a stir bar, 1,2,3,4-tetrahydroquinaldine or 1,2,3,4-tetrahydroquinoline (16.2 $\mu \mathrm{l}$ and $14.1 \mu \mathrm{l}$ respectively, $0.112 \mathrm{mmol})$, trimethoxybenzene $\left(10.0 \mathrm{mg}\right.$, internal ${ }^{1} \mathrm{H}$ NMR standard) and $\mathbf{3 a}$ or $\mathbf{3 b}$ (5 mol\% with respect to 1,2,3,4-tetrahydroquinaldine, 0.1 $\mathrm{ml}$ of $9.95 \mathrm{mg}$ 3a or $5.9 \mathrm{mg} \mathbf{3 b}$ in $1 \mathrm{ml}$ stock solution of appropriate solvent). For reactions run with a hydrogen acceptor, N-benzylideneaniline $(20.3 \mathrm{mg}, 0.112 \mathrm{mmol})$ was added. Dry solvent ( $3 \mathrm{ml}$ of toluene or $p$-xylene, sparged with $\mathrm{N}_{2}$ ) was then added to the flask. The mixture was then stirred and heated to just above its reflux temperature the 
reac $\left(115^{\circ} \mathrm{C}\right.$ for toluene, $145^{\circ} \mathrm{C}$ for $p$-xylene $)$ and aliquots were collected at 24 and 48 hours. The solvent was removed in vacuo and the resulting mixture was treated as above.

Procedure for 2-way dehydrogenation-hydrogenation of 1,2,3,4tetrahydroquinaldine For the optimized reaction run at $1.1 \mathrm{M}$ substrate loading, the dehydrogenation was carried out as described above, using $0.022 \mathrm{mmol}$ of either $\mathbf{1}$ or $\mathbf{3 b}$, $66 \mu \mathrm{L}(0.44 \mathrm{mmol})$ tetrahydroquinoline, $0.5 \mathrm{~mL}$ chlorobenzene and $5 \mathrm{mg}$ 1,3,5 trimethoxybenzene as internal standard. After heating at reflux under $\mathrm{N}_{2}$ for $24 \mathrm{~h}$, the reaction mixture was cooled to room temperature and a $50 \mu \mathrm{L}$ aliquot was taken for ${ }^{1} \mathrm{H}$ NMR analysis. $0.5 \mathrm{~mL}$ additional chlorobenzene, was added to the reaction mixture, and the reaction was stirred under an atmosphere of $\mathrm{H}_{2}$ for $24 \mathrm{~h}$.

\section{Acknowledgements:}

This material is based in on work supported by the Chemical Sciences, Geosciences, and Biosciences Division, Office of Basic Energy Sciences, Office of Science, U.S. Department of Energy (DE- FG02-07ER15909) (L.S.S., R.H.C.) as well as U.S. Department of Energy (DoE), Office of Science, Office of Basic Energy Sciences catalysis award (DE-FG02-84ER13297, catalysis) (M.G.M., R.H.C.).

\section{References}

${ }^{1}$ (a)Sartbaeva, A.; Kuznetsov, V. L; Wells, S. A.; Edwards, P. P. Energy Environ. Sci., 2008, 1, 79-85. (b) Armaroli, N.; Balzani, V. ChemSusChem, 2011, 4, 21-36 (c) Eberle, U.; Felderhoff, M.; Schüth, F. Angew. Chem. Int. Ed. 2009, 48, 6608-6630. (d) 
Makowski, P.; Thomas, A.; Kuhn, P.; Goettmann, P. Energy \& Environ. Sci., 2009, 2, 480-490. (e) Teichmann, D.; Arlt, W.; Wasserscheid, P.; Freymann, R. Energy \& Environ. Sci., 2011, 4, 2767-2773. (f) Fukuzumi, S.; Suenobu, T. Dalton Trans., 2013, $42,18-28$.

${ }^{2}$ Klebanoff L. Hydrogen storage technology: materials and applications. 1st ed. Taylor and Francis; 2012, p. 287-328.

${ }^{3}$ Mueller, K.; Voelkl, J.; Arlt, W. Energy Technol., 2013, 1, 20-24.

${ }^{4}$ (a) General Electric Global Research: http://ge.geglobalresearch.com/ (accessed December 28, 2014). (b) Luca, O.R.; Wang, T.; Konezny, S.J.; Batista, V.S.; Crabtree, R.H.; New J. Chem. 2011, 35, 998.

${ }^{5}$ Züttel, A.; Borgschulte, A.; Schlapbach, L. Hydrogen as a Future Energy Carrier; Wiley-VCH: Weinheim, Germany, 2008.

${ }^{6}$ (a) Moores, A.; Poyatos, M.; Luo, Y.; Crabtree, R. H. New J. Chem. 2006, 30, 1675.

(b) Clot, E.; Eisenstein, O.; Crabtree, R. H. Chem. Commun. 2007, 22, 2231-2233. (c)

Crabtree, R. H. Energy \& Environ. Sci., 2008, 1, 134-138. (d) Cui, Y.; Kwok, S.;

Bucholtz, A.; Davis, B.; Whitney, R. A.; Jessop, P. G. New J. Chem. 2008, 32, 10271037. (e) Jessop, P. G. Nature Chem. 2009, 1, 350-351. (f) Lu, R.-F.; Boethius,G.;Wen,S.-H.;Su,Y.;Deng,W.-Q.Chem.Commun.2009, 1751.

${ }^{7}$ (a) Mikami, K.; Ebata, K.; Mistudome, T.; Mizugaki, T.; Jitsukawa, K.; Kaneda, K. Heterocycles 2011, 82, 1371. 
${ }^{8}$ Ren, D.; He, L.; Yu, L.; Ding, R.-S.; Liu, Y.-M.; Cao, Y.; He, H.-Y.; Fan, K.-N. J. Am. Chem. Soc, 2012, 134 17592-17598.

${ }^{9}$ Dell'Anna, M. M.; Capodiferro, V. F.; Mali, M.; Manno, D.; Cotugno, P.; Monopoli, A.; Mastrorilli, P., Appl. Catal., A., 2014, 481 89-95. and references contained therein.

${ }^{10}$ Zhu, D.; Jiang, H.; Zhang, L.; Zheng, X.; Fu, H.; Yuan, M.; Chen, H.; Li, R.ChemCatChem, 2014, 6 2954-2960.

${ }^{11}$ (a) Wang, W. B.; Lu, S. M.; Yang, P. Y.; Han, X. W.; Zhou, Y. G. J. Am. Chem. Soc., 2003, 125,10536-10537.(b) Zhou, H.; Li, Z.; Wang, Z.; Wang, T.; Xu, L.; He, Y.; Fan, Q.-H.; Pan, J.;.Gu, L.; Chan, A. S. C. Angew. Chem. Int. Ed. 2008, 47, 8464 -8467 (c) Manaeka, Y.; Suenobu, T.; Fukuzumi, S. J. Am. Chem. Soc. 2011, 134, 367-374. (d) Wu, J.; Talwar, D.; Johnston, S.; Yan, M.; Xiao, J. Angew. Chem., Int. Ed. 2013, 52, 69836987. (e)Wu, J.; Barnard, J. H.; Zhang, Y.; Talwar, D.; Robertson, C. M.; Xiao J. Chem. Commun., 2013, 49, 7052--7054 (f) Cai, X.-F.; Huang, W.-X.; Chen, Z.-P. and Zhou, Y.G. Chem. Commun., 2014, 50, 9588. (g) Wendlandt, A. E.; Stahl, S. S. J. Am. Chem. Soc., 2014, 136, 11910-11913.

${ }^{12}$ Yamaguchi, R.; Ikeda, C.; Takahashi, T.; Fujita, K. J. Am. Chem. Soc. 2009, 131, 8410-8412.

${ }^{13}$ Chakraborty, S.; Brennessel, W. W.; Jones, W. D. J. Am. Chem. Soc., 2014, 136, 85648567. 
${ }^{14}$ Fujita, K.; Tanaka, Y.; Kobayashi, M.; Yamaguchi, R.; J. Am. Chem. Soc. 2014, 136, 4829-4832.

${ }^{15}$ Dobereiner, G. E.; Nova, A.; Schley, N. D.; Hazari, N.; Miller, S. J.; Eisenstein, O.; Crabtree, R. H., J. Am. Chem. Soc. 2011, 133, 7547-7562.

${ }^{16}$ Manas, M. G.; Graeupner, J.; Allen, L. J.; Dobereiner, G. E.; Rippy, K. C.; Hazari, N.; Crabtree, R. H.,. Organometallics 2013, 32, 4501-4506.

${ }^{17}$ Fujii, T.; Saito, Y. Chem. Comm. 1990 757-758. 


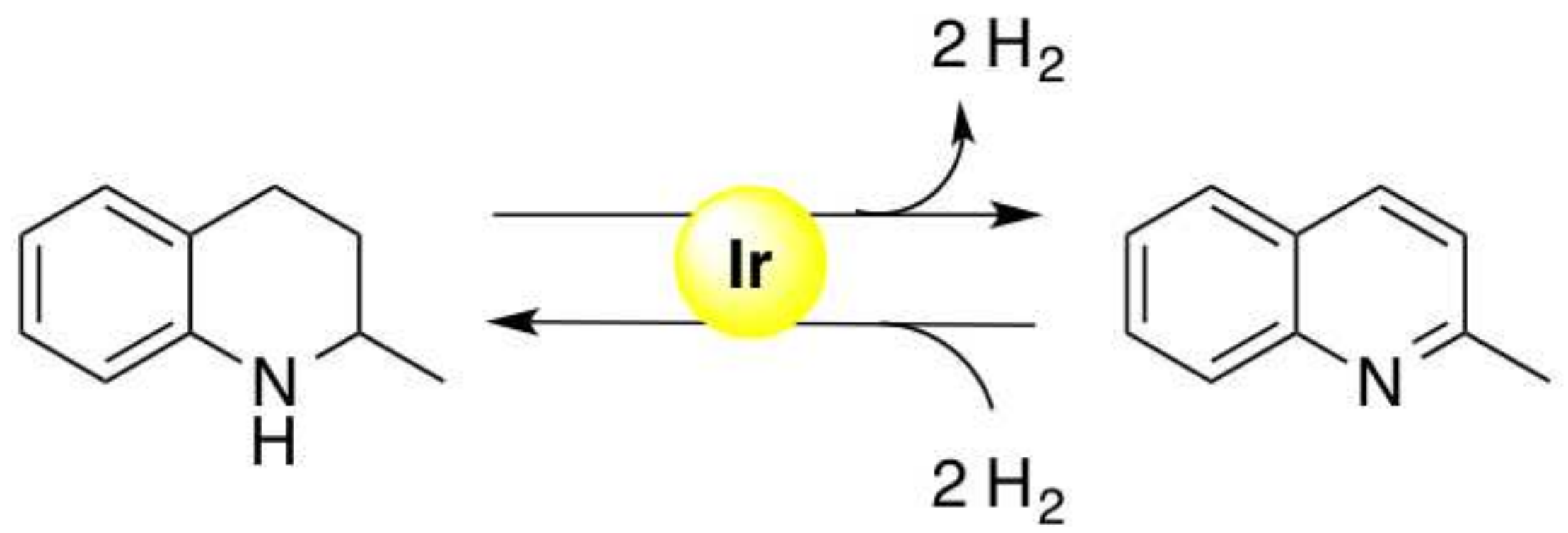

